\title{
Author Correction: The shaping of erosional landscapes by internal dynamics
}

\author{
Joel S. Scheingross (D, Ajay B. Limaye, Scott W. McCoy and Alexander C. Whittaker
}

Correction to: Nature Reviews Earth \& Environment https://doi.org/10.1038/s43017-020-0096-0, published online 06 October 2021.

The originally published article referred to 'aggressor' and 'victim' basins, following the terminology in reference 19. These terms have now been updated to 'expanding' and 'contracting' basins to avoid terminology that may be triggering for some readers.

Reference 37 after the statement 'Knickpoint generation near faults occurs at the timescale of co-seismic surface rupture or via exposure of slip along buried faults during river incision' was replaced with reference 178. The reference and the terms described above have been updated in the HTML and PDF versions of the manuscript.

https://doi.org/10.1038/s43017-021-00170-y I Published online 28 April 2021

(c) Springer Nature Limited 2021 